\title{
A Review of the Norwegian Health Care System
}

\author{
Dodanwalage Asela Kumar Perera \\ DOI: 10.29322/IJSRP.11.08.2021.p11602 \\ http://dx.doi.org/10.29322/IJSRP.11.08.2021.p11602
}

* Ministry of Health, Sri Lanka / Former researcher, Department of Global Health and Primary Care, University of Bergen, Norway.

\begin{abstract}
Norwegian health care system is increasing in size and complexity to meet the various health expectations of people. Norway provides a comprehensive health care service to the population through specialist care and the primary care system. The government is responsible for specialist health care delivery while 357 municipalities are responsible for primary care delivery.

This paper explores the Norwegian health system with special emphasis on financing, organization, information management and service delivery. This paper further discusses resource utilization and performance of the Norwegian health care system.

Data and information regarding health care system in Norway were collected and reviewed from resources including research papers, reports, documents, websites, informal interviews with experts and observations.

Health system of Norway has undergone several vital reforms and changes during the last two centuries. However, the tax-based finance system remains with minor changes. Norway is among the countries of highest per capita health expenditure as well as in terms of share of GDP. Being influenced by the ideology of the social welfare system, Norwegian health services developed on the principle of free access to all irrespective of their social status, location and financial capacity. With excellent health indicators and service standards, the Norwegian health system is considered one of the best health systems in the world.
\end{abstract}

Even with a high health care expenditure, the Norwegian health care system faces some issues and challenges.

Index Terms- Primary care, Specialist care, Epidemiological transition, Ageing population, Healthcare expenditure, Universal health coverage.

\section{INTRODUCTION}

Norway is a Scandinavian country situated in the northern part of Europe. A population of five million is sparsely distributed throughout the large territory of the country. The Norwegian healthcare system is built on the principle of equal access to the services irrespective of social class, income or place of residence. The responsibility of healthcare services provision to the population has been divided between the state and municipalities. Primary care including prevention, rehabilitation and long-term care, and home nursing care is delivered by the municipality (Romøren et al, 2011; Lindahl, 2016). Specialist health care services including laboratory, radiological and ambulatory care are delivered through government-owned hospital network. The private sector involvement in the Norwegian health care system is minimal and services are fully embedded in the public system. Nevertheless, in the care of substance abuse, rehabilitation and dental care services private organizations participation are significant. Most of the pharmacy chains are privately owned (Health statistics in Norway, 2018).

Norway experienced the epidemiological transition during 1960s. Before the 1950s the disease burden was mainly due to the Communicable Diseases. Since the 1960s the disease burden is mainly due to the Non-Communicable Diseases (NCDs). Cardiovascular disease, cancer, mental disorders, musculoskeletal disease, respiratory system diseases and injuries are the leading NCDs in Norway. The leading cause of death has changed from circulatory system diseases to cancer since 2017 (Health statistics in Norway, 2018).

At present Norway has a comprehensive healthcare system which is considered as one of the best healthcare systems of the world. However, despite high per capita health expenditure Norwegian healthcare system is facing several challenges. Since the 1970s the 
health care delivery model of Norway has undergone several major reforms mainly focusing to improve the efficiency, reduce the cost, empower the users and improve the quality and patient safety.

In Norway, even though, complementary and alternative medicine considered as an "alternative treatment", not referred to as an alternative "medicine". Besides, users are not entitled to patients' rights.

The main objective of this paper is to explore the Norwegian health system with special emphasis the financing system, organization structure, how service delivery is organized and information system. Further, this paper discuss the health system resource, health outcomes and challenges faced by the Norwegian health system. Data and information regarding health care system in Norway were collected and reviewed from resources including research papers, reports, documents, websites, informal interviews with experts and observations.

\section{FINANCING}

Table 01: The change of population, life expectancy, income and health expenditure from 2010 to 2018.

\begin{tabular}{|l|l|l|l|l|l|l|l|l|l|}
\hline Indicator & $\mathbf{2 0 1 0}$ & $\mathbf{2 0 1 1}$ & $\mathbf{2 0 1 2}$ & $\mathbf{2 0 1 3}$ & $\mathbf{2 0 1 4}$ & $\mathbf{2 0 1 5}$ & $\mathbf{2 0 1 6}$ & $\mathbf{2 0 1 7}$ & $\mathbf{2 0 1 8}$ \\
\hline $\begin{array}{l}\text { Population } \\
\text { (Millions) }\end{array}$ & 4.89 & 4.95 & 5.01 & 5.07 & 5.13 & 5.18 & 5.23 & 5.27 & 5.31 \\
\hline $\begin{array}{l}\text { GDP per } \\
\text { capita income } \\
\text { (USD) }\end{array}$ & 87693 & 100600 & 101524 & 102913 & 97019 & 74355 & 70460 & 75496 & 81697 \\
\hline $\begin{array}{l}\text { Health } \\
\text { expenditure } \\
\text { (\% of GDP) }\end{array}$ & 8.9 & 8.8 & 8.8 & 8.9 & 9.3 & 10.1 & 10.5 & 10.4 & 10.2 \\
\hline $\begin{array}{l}\text { Per capita } \\
\text { health } \\
\text { expenditure } \\
\text { (USD) }\end{array}$ & 7860 & 8900 & 8970 & 9241 & 9118 & 7566 & 7478 & 7815 & 8239 \\
\hline
\end{tabular}

Source; World Bank.

In 2018, Norway spent $10.2 \%$ of GDP on health care and public financing accounts for $85 \%$ of this. The health expenditure for GDP ratio was $8.9 \%$ in 2010 and has increased by $1.3 \%$ when comes to 2018 . Since 2010 to 2018 the share of GDP of health care increased annually, but it has declined by $0.3 \%$ in 2018 when compared to 2016 . Current health expenditure per capita in Norway was USD 8621 in 2020 (Statistics Norway,2021). In 2020, Norway has the highest per capita health expenditure (PPP) among the Nordic countries and remains the third place in the world (OECD, 2021). A positive relationship can be observed between per capita income and per capita health expenditure from 2010 to 2018.

Norway has the 'Beveridge Model' tax-based health financing system. The Norwegian health system has three main sources of revenue: general taxation revenues (accounting for $74 \%$ of the total), insurance contributions to the national insurance scheme (11\%) and private expenditure (15\%), which in Norway consists mainly of out-of-pocket (OECD, 2019; World Bank, 2021). All residents and people who have come to work in Norway legally are eligible to get a cover of the National Insurance Scheme (NIS). NIS is financed by the contribution from employees, employers and self-employed. As can be seen, the NIS covers a great deal of risks related to foregone income and expenses (Healthcare System in Transition, Norway, 2000). The municipal health care system is partly financed through the national budget by way of general and earmarked contributions and partly through municipal taxes and the patients' out-of-pocket payments (Financing of Health Care in the Nordic Countries, 2013). 


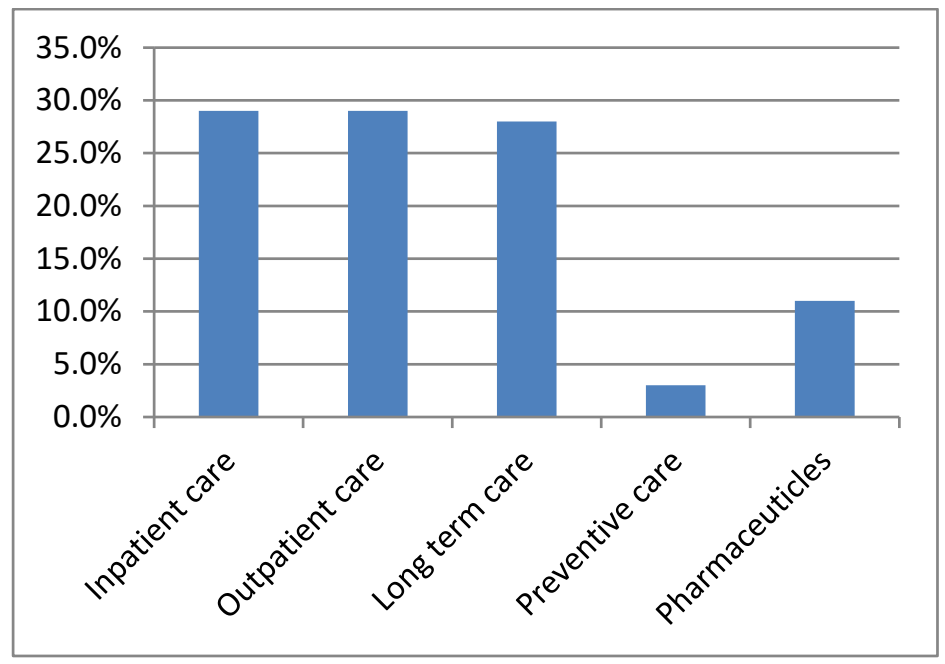

Figure 1: Health expenditure according to the function of care. Source: OECD, 2019

Norway spends nearly one-third of the health budget on long-term care, which is the highest in the European Union, in order to meet the raising care demand of steadily growing elderly population. On the other hand, the share of total health spending on pharmaceuticals and medical devices of just over $10 \%$ was the second lowest and has decreased over the past decade (OECD, 2019).

Universal health coverage has been achieved for all residing legally in Norway. All medical treatments are free of charge for any person less than sixteen years of age. However, except for inward care and home-based nursing care, copayments are applicable to other services for the person above sixteen years of age until becoming eligible for an exemption card. In practice, national health care covers planned and acute primary, hospital, and ambulatory care, rehabilitation, and outpatient prescription drugs on the formulary (the "blue list"). It also covers dental care services for children up to 18 years of age and other prioritized groups, such as people with some chronic diseases, patients with chronic mental disabilities, and patients in nursing homes (Lindahl, 2016). Adults' dental care is not covered by the costsharing and account for the largest share of out of pocket expenditure.

Public hospitals became a property of the state since the implementation of Norwegian health reforms in 2002. Funding for the running of hospitals is raised almost exclusively by taxation, although a major part of it is channelled through a system of "national health insurance" (Gronliea (2006). According to Heimly et al (2011), all public hospitals are operated under four regional health authorities and account $43 \%$ of annual health expenditure. Central Government supplies the regional health authorities with a global budget so they can meet the political health goals for the specialist health care (Financing of Health Care in the Nordic Countries, 2013). The Ministry of Local Government and Local Authorities is responsible for the distribution of block grants from the state. These grants are allocated according to a formula including the age/sex composition of the population, demographic indicators and variables related to health needs (e.g., mortality rates) (Healthcare System in Transition: Norway, 2013). During the 1970s hospital recurrent cost continuously increased. Problems aroused who should be paid this extra cost of financial inefficiency. When compare health care expenditure in the mid-1990s, Norway's level is now more than 50 per cent higher than in its neighboring Sweden and Denmark (Magnussen, 2009). Mechanisms such as splitting purchasers and providers and using activity-based financing have been implemented with the clear purpose of increasing efficiency (Magnussen, 2009).

\section{ORGANIZATIONAL STRUCTURE}

The Norwegian health care system is built on three principles of equal access, decentralization and free choice of provider. All inhabitants of the country shall have the same access to services, independent of social status, location and income (Healthcare System 
in Transition: Norway, 2003; Magnussen, 2009; Lindahl, 2016). Norway has a three-level politico-administrative system. The highest level is the state, the second level consists of nineteen counties (fylkes) and the third level is 357 (Statistics Norway, 2021) local authorities or communes. More than $60 \%$ of communes in the country have less than 5000 inhabitants.

\section{Organization of the Health System in Norway}

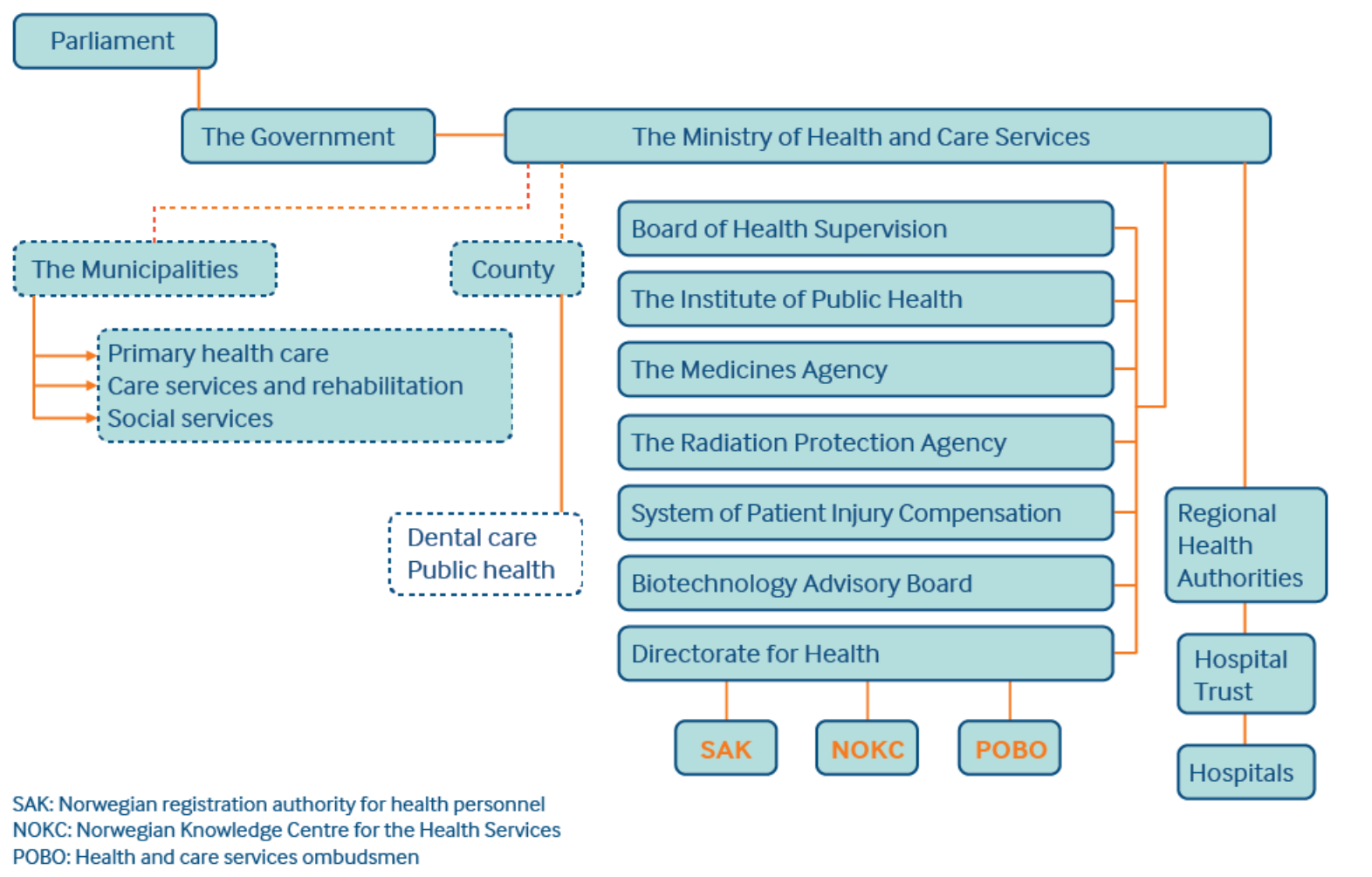

Source: A. K. Lindahl, Norwegian Knowledge Centre for Health Services, 2015.

Figure 2: Organization of health system of Norway

The present organizational structure of the Norwegian health care system consists of four administrative levels including the state, Regional Health Enterprises (RHE), Counties and Municipalities. The state has several roles in health care provision including as owner, policymaker and regulating. At the state level, the governing body is the parliament and implementing authority is the Ministry of Health. Political decisions are made by the government. Ministry of health led by the minister of health translates those political decisions to the practice through healthcare.

In Norway, health care delivery is organized as the primary health care at municipality level and secondary/specialized care at county level.

The Ministry of Health is responsible for providing statutory specialist care. It owns the RHEs, which are separate legal subjects, governed by independent boards known as Regional Health Committees (RHCs) (Healthcare System in Transition: Norway, 2000,), initially, there were five but later came to four. The four RHCs are responsible for supervising specialist inpatient somatic and psychiatric care, as well as treatment for alcohol and substance abuse (Lindahl, 2016). Introducing RHEs directed more towards centralization of health service delivery particularly hospital care and at the same time creating a room for some extend resource sharing among the counties. Gronliea (2006) says state regional enterprise is just as much the hegemonic politico-administrative "solution of today" as county ownership was in the 1960s and 1970s. The regional health committees are responsible for the development of regional health 
plans for the four years, following high priorities of nationally and county. Despite to the main objective of the regional health plan to ensure the people participation in health planning, it acts as a tool for more centralization of the planning process.

The state owns public hospitals are operated with a combined budget of over NOK 75 billion (Government.no, 2019). Among those, there are four major public somatic hospitals with over 800 bed capacity of each. The number of privately own hospitals are very few. Critical or advanced emergency care including ambulance and air ambulance service is also organized within the specialist care system. The ministry of health responsible for designing, implementation and monitoring of public health services through Directorate of Health, Norwegian Public Health Institution and National Board of Health Supervision. Services are delivered by Municipal Medical Officers, GPs, Public Health Midwives and Public Health Nurses at the municipality level. Local municipalities have been given the responsibility of providing all primary health care services by the Local Authority Health Care Act in 1984.

Primary healthcare services are mainly organized based on general practitioners (GPs) care. There are 22500 doctors in Norway and around 4500 works as GPs (OECD, 2018). Among these, 54\% are specialists in general practice, and 90\% work in group practices (Rotveit, 2015). Primary mental health care is provided by GPs and municipal psychologists (Lindahl, 2016). After hour primary emergency care service centers known as 'Legevakt' are responsible for providing acute and emergency care needs of the patients. Although patients are free to select a hospital for elective care services but not for the emergency care services.

The Norwegian Board of Health is an independent body function in collaboration with nineteen county medical officers. Main responsibilities of the board are promoting quality, patient safety and legal safeguards within the Norwegian health sector. The board is also responsible for the supervision of all health services and all health personnel, dealing with complaints and advice and guidance on health matters to the Ministry of Health and Social Affairs, the health sector and the general public.

The Norwegian Medicines Agency is responsible for marketing authorization, deciding the maximum prices of drugs, classification, vigilance and providing information on medicine to prescribers and the general public. Determines which medications to reimburse for outpatients based on Blue Chit also another key function of the Medicine Agency.

The Norwegian Institute of Public Health (NIPH) is responsible for the availability, quality, easy access and utilization of medical information and data in the Norwegian health care system.

\section{HEALTH INFORMATION SYSTEM}

Various types of health data are collected by national registers. These central registers cover the entire population and include a wide range of data. In 2012, there were 15 central registers in addition to 54 clinical registers. None of the registers requires patients' consent to collect data and reporting is mandatory for health-care providers (Health system in transition, 2013).

Directorate of eHealth is responsible for planning, implementation and regulation of information technology health information sharing of over 5 million people of Norway. Each resident legally resides in Norway gets 11 digits personnel identification number (PIN). The PIN is linked with Electronic Health Record (EHR) of the person concerned. The electronic health record has been characterized as a hub of information in health care (Heimly et al, 2011). EHR gives the facility to communicate among the health care providers by ePriscription, eReferrals, electronic discharge letters, sick leaves, laboratory investigation results and radiological images. In January 2005 the ePriscription programme started in Norway, which is aiming to established a national fully electronic information chain for prescription drugs of medical supplies (Doupi et al, 2010)

Health authorities are responsible to notify all births in Norway to the medical birth registry (MBRN) electronically. The MBRN collects data regarding maternal health before and after pregnancy, complications of pregnancy and childbirth, information about medications used in pregnancy, birth complications and congenital abnormalities. 
The NIPH runs the Norwegian Surveillance System for Communicable Diseases (MSIS) and contributes to international surveillance in collaboration with the European Centre for Disease Prevention and Control and WHO (Health care system in transition, Norway, 2013). In Norway, seven communicable diseases are notifiable under three categories to the NIPH and Municipality Medical Officer in the patient's municipality of residence.

\section{Resources Utilization AND Performance}

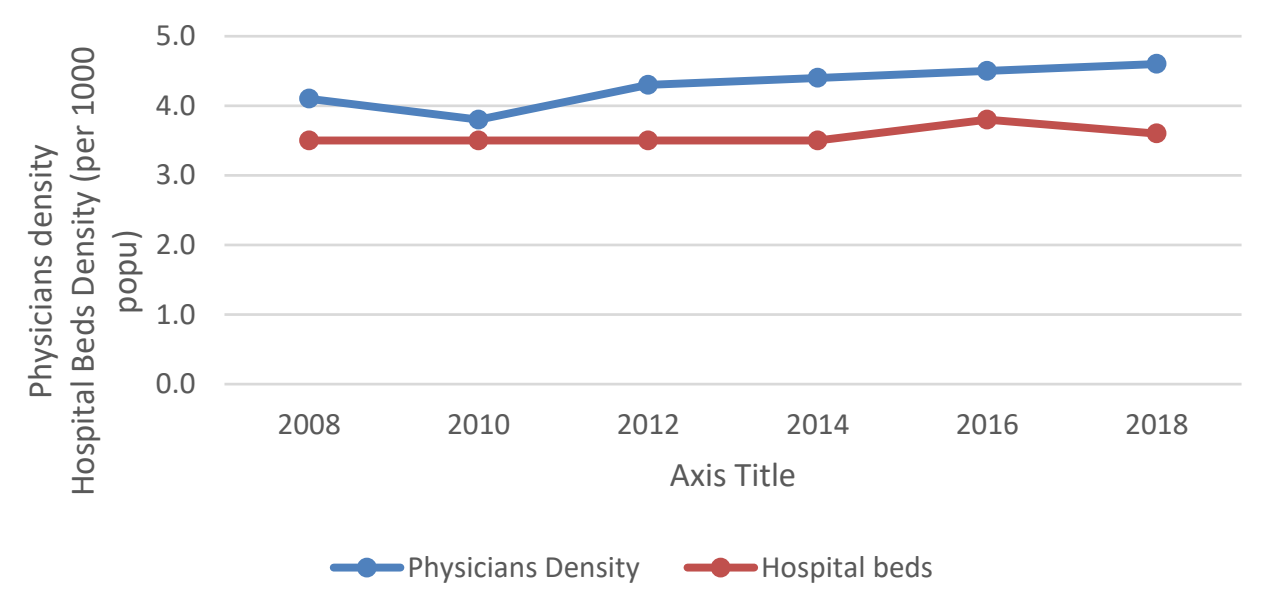

Figure 3: Changes in physicians' density \& hospital bed density since 2008. Source; World Bank

Even though hospital bed density remains constant during the last decade, the number of physicians has increased significantly.

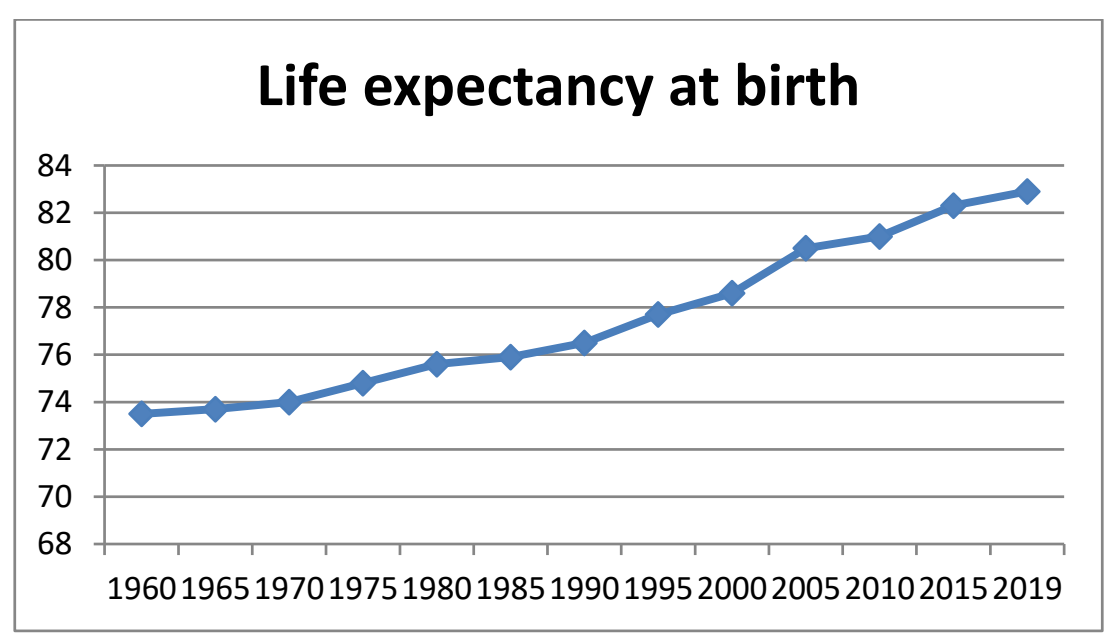

Figure 4: Life expectancy at birth. Source; World Bank Data \& Statistics Norway

The life expectancy of Norway has increased steadily over the past six decades. Life expectancy at birth was 84.3 years for females and 80.9 years for men in 2017 (statistics Norway, 2018), is one of the highest in the world. Life expectancy at 65 years of age was 21.6 years in 2017 (OECD, 2018) and second highest in Scandinavia. Even though a gender gap exists in life expectancy at 65 years of age, there is no gender gap in the number of healthy life years, because women tend to live a greater proportion of their lives after age 65 with some health issues and disabilities. Furthermore, Life expectancy at birth in Norway increased by nearly four years from 2000, reaching 82.7 years in 2017, nearly two years above the EU average (OECD, 2019). 
Annually, about 70000 people are treated in hospitals. In 2016, more than 40000 people died in Norway. Cardiovascular diseases and cancer were accounted for more than half of all deaths (Health statistics in Norway, 2018). However, with various health interventions, the number of new cases of Myocardial Infarction (MI) per 100000 people per year as well as mortality is declining (NIPH, 2018).

In 2016, Norway age standard rate of mortality from treatable causes was 62 per 100000 population (OECD, 2019) and it was the lowest in Europe along with Ice Land.

Table 2: Selected health status indicators in Norway

\begin{tabular}{|l|l|l|l|l|l|l|}
\hline & 2000 & 2004 & 2008 & 2012 & 2016 & 2018 \\
\hline $\begin{array}{l}\text { MMR per 100 000 live } \\
\text { births }\end{array}$ & 6.0 & 5.0 & 4.0 & 3.0 & 3.0 & 2.0 \\
\hline IMR per 1000 live births & 3.9 & 3.4 & 2.9 & 2.4 & 2.1 & 2.1 \\
\hline NMR per 1000 live births & 2.7 & 2.4 & 2.0 & 1.7 & 1.6 & 1.5 \\
\hline $\begin{array}{l}\text { Immunization coverage, } \\
\text { DPT(\%) }\end{array}$ & na & 99 & 99 & 99 & 100 & 99 \\
\hline
\end{tabular}

Data Sources; World Bank, World Data Atlas

Maternal mortality has reduced continuously during the last few decades and remain as one of the lowest in the globe. Infant Mortality Rate was 3.9 per 1000 live births in the year 2000 and further reduced up to 2.1 per 1000 live births in 2018. Although vaccination is not compulsory in Norway, vaccines for 14 diseases are offered free of charge by the national childhood immunization program to all children residing in Norway. Measles vaccine coverage at the age of two years is 96\% in 2017 (NIPH, 2018).

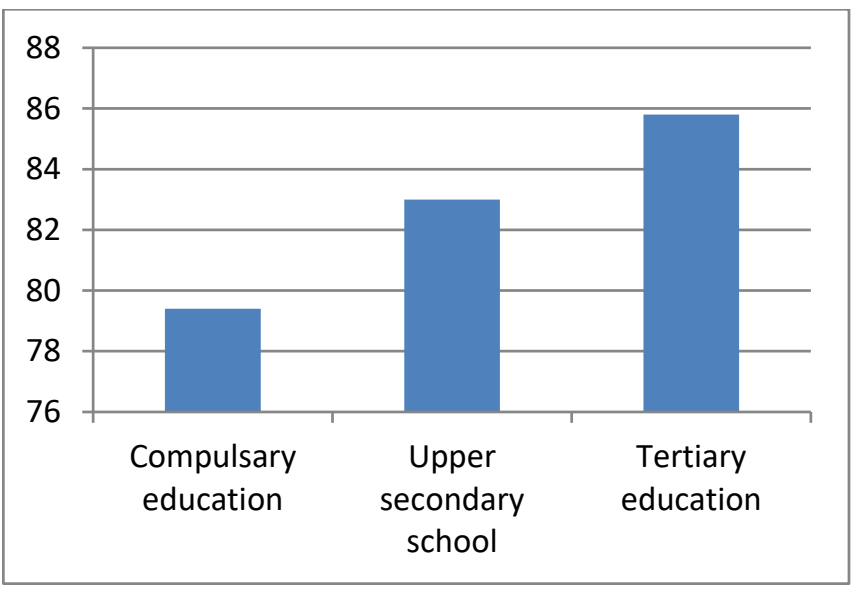

Figure 5: Life expectancy by educational attainment, Norway - 2017

Data Source; Norhealth

Those who have completed higher education show 6.4 years higher life expectancy than those who have primary education. Despite a highly financed, well-structured and universally accessible health system, even in Norway, health inequalities exist among different population groups. 


\section{Challenges}

\section{Long waiting time}

Long waiting time for health care is an important health policy issue in many countries may have introduced some form of national waiting time guarantee (Viberg et al, 2013). A study done by Siciliani and Hurst (Cited by Viberg et al) of OECD countries in 2003 concluded that "waiting time is a serious health policy issue in 12 countries including Norway. Viberg et al in 2013 found that average waiting time for elective surgery (after reference done) is 75 days in Norway. This finding has been confirmed by the ministry of health saying that there are still unacceptable waiting times within some specialist fields (Health master plan, 2007-2010).

In Norway, it is a responsibility of specialists' health service provider that provides health services to the patients within the guaranteed maximum waiting time. According to the Norwegian Health Directorate, specialist health service is responsible for notifying the Norwegian Health Economic Administration (HELFO) if it sees in advance that it will be unable to provide healthcare to a patient within the guaranteed maximum waiting time. There are geographical differences in waiting times and the prioritization of groups with different diagnoses (Health master plan, 2007-2010).

Norway also has a system of individual waiting-time guarantees for patients. Prioritization guidelines have been developed to help hospital physicians determine the appropriate waiting time for each patient (Health care system in transition, 2013).

In the past 30 years, five government commissions were appointed to evaluate principles for priority setting in the health sector. Severity, expected health outcomes and cost-effectiveness are the main criteria that have been formed the foundation for priority setting in health care in Norway (Principles for priority setting in health care in Norway, 2017).

Waiting time could be considered as a measurement of the inefficiency of healthcare delivery. If the waiting time prolonged it will cause to patient suffering and create dissatisfaction among the public.

2. High healthcare expenditure

Impressive health system performance still comes at a cost in Norway, with the country remaining one of the biggest spenders in the OECD in 2013. Total per capita health expenditure (adjusted to PPP) in 1995 was 1862 USD. But it is continuously rising and on 2015 total per capita health expenditure was 5862 USD (adjusted for purchasing power parity), well above the OECD average of 3453 USD (OECD, 2015) Health care expenditure as a percentage of GDP is a little bit above the European average.

3. Rural areas face difficulties in attracting GPs to public services

Some of the main reasons for the difficulty in recruiting and retaining doctors include, geographically long distance to the closest hospital, heavy workload and professional isolation. Stagens in 2019 says that more than 50\% of newly graduated medical doctors are female. Therefore, good schooling, shopping and social opportunities are becoming high of the list.

4. Fragmentation of services and poor coordination among municipalities and hospitals.

Romoren et al said even though the primary and secondary care system is fairly systematically organized within each sector, there is a lack of mediating structure for the relation and interaction between two sectors. They further said this weakness is further aggravated by the fact that each sector belongs to separate levels of public administration: local and national.

Many users and their relatives experience the health service as disjointed without a clear allocation of responsibility for the interaction between the various actors (Health master plan, 2007-2010).

Although, there were several policy initiatives for better integration of healthcare since 2001, still successful solution could not be implemented.

5. Rapidly ageing population 
When considering the 2018 population composition $11 \%$ of the Norwegian population is age above 70 years. This figure will be doubled by the year 2060. The number as well as the proportion, of the elderly population, is expected to increase in coming years. The current proportion of $4.2 \%$ of the age above 80 years of age will double over the course of two decades (NIPH, 2018) Healthcare services need to be adjusted to meet the changing health requirements of the elderly population.

\section{CONCLUSIONS}

Even though the Health system of Norway has undergone several vital reforms and changes during the last two centuries, the tax-based finance system remains with minor changes. Because of health care delivery system is demarcated and organized as primary and specialist services, primary health care services are more closure to the people and community. The Norwegian health system is considered one of the best health systems in the world due to the universal health coverage, excellent health indicators and service standards. Even with a high health care expenditure, the Norwegian health care system faces some issues and challenges of equality, dynamicity of demand and changing population structure.

\section{REFERENCES}

Doupi P, Renko E, Giest S; ehealth strategy, Norway, 2010.

Financing of Health Care in the Nordic Countries, Nordic Medico Statistical Committee Copenhagen, 2013.

Government.no; Official government website - Norway, 2019

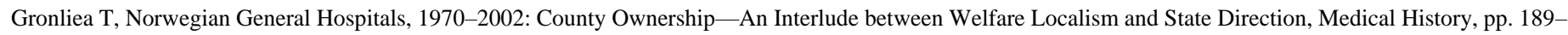
208, 2006

Health Care Systems in Transition - Norway, The European Observatory on Health Care Systems, 2000.

Health Care Systems in Transition - Norway, The European Observatory on Health Care Systems, 2003.

Health Care Systems in Transition - Norway, The European Observatory on Health Care Systems, 2013.

Health Master Plan, Norway, 2007 - 2010.

Health statistics in Norway, Public health report - short version published by National Institution of Public Health, Norway 2018.

Heimly V, Grimsmo A, Faxvaag A; Diffusion of electronic health record and electronic communication in Norway, 2011.

Helsenorge.no

Lindahl A K, The Norwegian Health Care System, Norwegian Institute of Public Health, 2016

Magnussen J, The Scandanavian Healthcare System, Medical Solutions, May 2009.

OECD, Data, 2018. https://data.oecd.org/

OECD, Data 2021. https://data.oecd.org/

OECD; Health at glance, 2015.

OECD; Country health profile: Norway, 2019.

Principles of priority setting in health care, Ministry of health and care services, 2017.

Public health report, NIPH, 2018. 
Romoren T I, Torjesen D O, Landmark B; Promoting coordination in Norwegian health care, International Journal of Integrated Care, Jan-Dec 2011.

Rotveit G, Primary care in Norwegian health care system, 2015: Online; euprimarycare.org.

Statistics Norway, ssb.no/en/helsestst, 2019.

Statistics Norway, ssb.no/en/helsestst, 2021.

Westin S, The beginning of the NHS - and the impact on Norwegian health care, www.michealjournal.no, 2011.

World Bank Data, 2021; www. https://data.worldbank.org

\section{AUTHORS}

First Author - Dodanwalage Asela Kumar Perera,

MBBS, MSc (Medical Administration), MD (Medical Administration),

Ministry of Health, Sri Lanka/Former researcher, Department of Global Health and Primary Care, University of Bergen, Norway. and email address; sjwprr@yahoo.com

Correspondence Author - Dodanwalage Asela Kumar Perera,

email address; sjwprr@yahoo.com

alternate email address; traveldrasela@gmail.com,

contact number; +94 740350063 